\title{
A violência como tema transversal aos estudos sobre a deficiência: interconexões necessárias
}

\section{Violence as cross-cutting theme in disability studies: needed Interconections}

\section{La Violencia como tema transversal a los estudios sobre la discapacidad: interconexiónes necesarias}

\author{
Aline Wanderer* \\ Tribunal de Justiça do Distrito Federal e dos Territórios - TJDFT, Brasília, Distrito \\ Federal, Brasil
}

\section{Regina Lúcia Sucupira Pedroza**}

Universidade de Brasília - UnB, Brasília, Distrito Federal, Brasil

\begin{abstract}
RESUMO
A violência é um importante tema transversal aos estudos sobre a deficiência. Quando exercida contra pessoas com deficiência, liga-se a elementos de estigmatização, quebra do direito ao pleno desenvolvimento e consequente exclusão social. Neste trabalho, por meio de análise crítica da literatura, problematiza-se a concepção de uma vulnerabilidade necessariamente aumentada desses sujeitos a sofrerem violência em razão de uma condição assumida como sendo inerente a eles, para localizar a temática no âmbito das relações interpessoais, familiares, comunitárias e institucionais. A psicologia deve contribuir para construir políticas públicas que atuem no enfrentamento à violência contra pessoas com deficiência, concebendo seu desenvolvimento como processo contínuo, dinâmico, não delimitado a priori e qualitativamente diferenciado, em que exercem papel ativo. É essencial uma educação para os direitos e a cidadania, bem como a ação do Estado na criação de instâncias de cuidado, em sentido amplo.

Palavras-chave: deficiência, violência, vulnerabilidade, inclusão social, políticas públicas.
\end{abstract}

\begin{abstract}
Violence is an important cross-cutting theme in disabilities studies. When violence occurs against people with disability, it is related to stigmatization elements, breach of the right to full development and consequent social exclusion. This article, starting from a critical analysis of the literature, discusses the conception of a necessarily increased vulnerability of these individuals to suffer violence because of a condition which is assumed to be inherent to them, to locate the issue in interpersonal, familiar, communitarian and institutional relationships context. Psychology must contribute to the development of public policies that deal with violence against people with disability, considering their development as a continuous, dynamic, and qualitatively different process, which is not limited
\end{abstract}


a priori and in which people perform an active role. An education for rights and citizenship is essential, as well as State's action in creating instances of care, understood in a broad sense.

Keywords: violence, disability, vulnerability, social inclusion, public policies.

\section{RESUMEN}

La violencia es un importante tema transversal a los estudios sobre la discapacidad. Cuando ejercida contra las personas con discapacidad, se une a elementos de estigmatización, violación del derecho al pleno desarrollo y consecuente exclusión social. En este trabajo, por medio del análisis crítico de la literatura, se cuestiona la concepción de una vulnerabilidad necesariamente aumentada de estes sujetos a sufriren violencia a causa de una condición asumida cómo siendo inherente a ellos, para ubicar el tema en el contexto de las relaciones interpersonales, familiares, comunitarias e institucionales. La psicología debe contribuir a la construcción de políticas públicas que actúen en el enfrentamiento a la violencia contra personas con discapacidad, concebindo su desarrollo como proceso continuo, dinámico, no delimitado a priori y cualitativamente diferenciado, en que ejercen rol activo. Es esencial la educación para los derechos y la ciudadanía, así como la acción del Estado en la creación de instancias de cuidado, en un sentido amplio.

Palabras clave: violencia, discapacidad, vulnerabilidad, inclusión social, políticas públicas.

\section{Introdução}

Este trabalho constitui um desdobramento das reflexões suscitadas durante a elaboração da dissertação de mestrado da primeira autora, sob orientação da segunda (Wanderer, 2012). A partir de uma análise crítica da literatura, tem por objetivo explorar os pontos de encontro entre os objetos de estudo da deficiência e da violência, apontando a necessidade de que suas interconexões sejam abordadas pela psicologia e áreas afins. Explorando tais objetos, é possível apontar o caráter histórico apresentado por ambos, demonstrando que suas significações estão vinculadas a aspectos contextuais, socioculturais, econômicos e políticos de cada época.

A análise histórica da deficiência nos revela a construção e a consolidação de processos de exclusão social, segregação, preconceito e estigmatização dos indivíduos que estão caracterizados por diferenças biológicas ou psicológicas que são tomadas como desvios da normalidade e expressão de menos valia social. A visão biomédica do fenômeno contrapõe-se àquela que o compreende enquanto construção social e que permite reconfigurá-lo como dimensão de luta política. A inserção da deficiência no campo da defesa de direitos humanos e a consequente proposta de instauração do paradigma da inclusão social configuram um campo de mudanças e contradições vivas, que nos convida a contínuas e renovadas reflexões, tanto do ponto de vista científico quanto ético (Vigotski, 
1929/1995; Pessotti, 1981; Omote, 1994; Linton, 1998; Aranha, 2001; Tunes, 2003; Lacerda, 2006; Clímaco, 2010).

Já a significação do que é entendido por violência vem se alterando ao longo do tempo, o que nos leva, hoje, a classificar como tal uma série de eventos e relações que outrora eram entendidos como legítimos e aceitáveis nos âmbitos público e privado (Galinkin, 2007; Wieviorka, 2007). Conceito complexo e multifacetado, a violência é analisada como se relacionando ao poder, proliferando-se propostas de classificação por tipologia e natureza (Chaui, 1984; Krug, Dahlberg, Mercy, Zwi, \& Lozano, 2002; Minayo, 2009; Guimarães, 2010; Medeiros, 2010). A violência passa a ser considerada como problema de saúde pública, havendo estudos que indicam caminhos para seu enfrentamento, com base na análise de conceitos como fatores de risco e proteção, prevenção da violência e promoção da saúde (Krug et al, 2002; Schraiber, D'Oliveira, \& Couto, 2006). Seu enfrentamento implica a necessidade de profundas transformações nos modos de relação social, sendo que o tema também vem sendo vinculado à questão dos direitos humanos e suscitando tensões no diálogo entre público e privado.

Consideramos haver subsídios que nos indicam possíveis interrelações entre ambas. A forma como a violência é definida em conexão com relações assimétricas de poder, e o reconhecimento de processos perversos de exclusão social e opressão das pessoas com deficiência são elementos que nos levam a postular que a violência deveria ser estudada como um importante tema transversal no campo da produção de conhecimentos sobre a deficiência.

Neste trabalho, abordamos a deficiência a partir do que ficou conhecido como modelo social. Nessa perspectiva, a deficiência (disability ${ }^{1}$ ) passa a ser concebida como uma construção social, vinculada a uma estrutura social excludente, que produz opressão e segregação dos indivíduos, em função de uma realidade biológica inscrita num corpo com lesão (impairment). A partir dessas primeiras formulações, houve diversos avanços e propostas que concebem a construção social da deficiência, que possibilitam a caracterização das pessoas com deficiência enquanto grupo que compartilha a opressão pela norma e a experiência da deficiência, para além das diferenças biológicas catalogadas pelo saber médico. Há uma reivindicação, por parte desse grupo, em poder escolher como nomear e descrever sua própria experiência, optando, por vezes, por manter termos provindos de um modelo médico de deficiência, com o objetivo de ressignificá-los, de estabelecer uma provocação metacomunicativa que leve à reflexão acerca da opressão que encerram. A deficiência passa a não decorrer, primordialmente, de uma circunstância biológica, mas de como ela exerce impacto nos outros, em uma audiência social. $\mathrm{O}$ foco é deslocado do âmbito individual para inscrever-se no social, constituindo a deficiência no campo da luta 
política por direitos civis por meio da responsabilização pública. Não há interesse em se apagar a linha entre deficientes e não-deficientes, mas sim de demarcá-la, apontando a peculiaridade de se pertencer ou não a um grupo que enfrenta discriminação, opressão e silenciamento (Omote, 1994; Linton, 1998; Clímaco, 2010).

Nesse sentido, ao inter-relacionarmos os temas da deficiência e da violência, importa destacar que não efetuamos recortes que apontem especificidades relativas a alguma forma específica de deficiência (sensorial, física ou intelectual, por exemplo), visto que o foco de análise é deslocado para o modo como deficiência e vulnerabilidade à violência são construídas no âmbito das relações interpessoais, familiares, comunitárias e institucionais.

\section{Interconexões entre deficiência e violência: contribuições e questionamentos a partir da Literatura}

Os estudos que abordam a relação entre deficiência e violência são escassos e incipientes, notadamente no Brasil. Embora haja tendência a se considerar que as pessoas com deficiência têm maior probabilidade de sofrer episódios de violência, não há clareza quanto à incidência quantitativa do fenômeno, às formas em que tais violências apareceriam e em quais contextos, e aos fatores que vinculam violência e deficiência.

Em interessante revisão da literatura internacional relativa à violência contra crianças com deficiência, Berastegui Pedro-Viejo \& GomezBengoechea (2006) apontam que a infância com deficiência, historicamente, foi aquela que sofreu a maior carga de discriminação e quebra de direitos. As autoras descrevem que os estudos que relacionam deficiência e violência têm enfocado três direções: a criança com deficiência como vítima de violência; a deficiência como resultado da violência; e a pessoa com deficiência como estando em maior risco de se tornar autora de violência. Entendemos que os três níveis de análise são importantes e interdependentes.

A literatura aponta que muitos adultos adquiriram deficiências como consequência de maus-tratos e/ou abuso sexual na infância ou que impedimentos biológicos podem ser ocasionados pela ocorrência de violência doméstica contra as mulheres durante a gestação (Williams, 2003; Berastegui Pedro-Viejo \& Gomez-Bengoechea, 2006; Cruz, Silva, \& Alves, 2007). A constatação da possibilidade de que a deficiência apareça como resultado de situações de violência é considerada como estando inserida em um ciclo vicioso entre violência e deficiência, em que a primeira promove o aparecimento da segunda e isso, por sua vez, alimenta a vulnerabilidade do indivíduo com deficiência a participar de ciclos de violência. Nesse sentido, aponta-se que prevenir a ocorrência e o agravamento de deficiências 
também deveria ser parte das agendas para a prevenção da violência.

Adicionalmente, alguns estudos abordam que a existência de deficiência intelectual ou atraso global no desenvolvimento poderia redundar em maior risco para que pessoas com tais condições exercessem maus-tratos ou negligência em relação aos filhos, por possuírem dificuldades em compreender, antecipar e dar suporte a mudanças próprias ao desenvolvimento típico das crianças (Williams, 2003; Berastegui Pedro-Viejo \& Gomez-Bengoechea, 2006; Postalli, Munuera, \& Aiello, 2011). Outra questão levantada refere-se à possibilidade de haver uma maior representatividade da prática de agressões sexuais por adultos com deficiência intelectual, Embora não exista consenso a tal respeito (Berastegui Pedro-Viejo \& GomezBengoechea, 2006).

Importa analisar com redobrado cuidado a atribuição de maior probabilidade de que pessoas com deficiência intelectual tornem-se agressores sexuais ou ofereçam risco aos filhos quando no exercício da parentalidade. A análise de resultados empíricos nesse sentido necessita contar com um olhar crítico em sua interpretação por parte dos pesquisadores, problematizando-se uma possível essencialização da deficiência como fator que, em si mesmo, gera limitações no desenvolvimento de papéis sociais da vida adulta, como o cuidado de crianças ou o exercício responsável e prazeroso da sexualidade. Importa considerar as complexidades da própria atribuição do diagnóstico de deficiência intelectual (Gould, 1991; Tunes, Rangel, \& Souza, 1992; Schiff, 1994; Tunes \& Danezy Piantino, 2001; Dias, 2004; Assis, 2009), quanto à negação que os indivíduos assim rotulados encontram para a garantia de direitos fundamentais e para o acesso a experiências que promovam seu pleno desenvolvimento, inclusive no tocante à aprendizagem de convenções sociais quanto às relações interpessoais e exercício da sexualidade (Soares, Moreira, \& Monteiro, 2008; Bastos \& Deslandes, 2009; Maia \& Ribeiro, 2010; Messa \& Fiamenghi Jr., 2010).

Um maior número de produções têm se dedicado a explorar em que medida pessoas com deficiência estariam mais vulneráveis a sofrer violência, seja na infância e adolescência, seja na idade adulta. Embora haja estudos empíricos que não encontraram diferenças na incidência de maus-tratos contra crianças com e sem deficiência (Olivan, 2002, citado em Berastegui Pedro-Viejo \& GomezBengoechea, 2006), a maior parte dos estudos tende a apontar uma vulnerabilidade aumentada das pessoas com deficiência para serem violentadas, sendo o risco agravado quando há múltiplas deficiências e/ou se pertence a mais de um grupo de risco (Williams, 2003).

Levantamentos sistemáticos que busquem quantificar a incidência de situações de violência contra pessoas com deficiência inexistem no Brasil e apresentam resultados bastante variáveis em âmbito 
internacional. Alguns autores citam estudos epidemiológicos internacionais que apontam que, estatisticamente, há maior incidência de situações de violência contra pessoas com deficiência (Williams, 2003; Barros, Williams, \& Brino, 2008; Cavalcante \& Minayo, 2009). Não há consenso, além disso, quanto às formas de violência mais frequentes contra crianças e adultos com deficiência. A maioria dos estudos indica que a violência ocorreria mais frequentemente no âmbito doméstico; que haveria maior vulnerabilidade ao abuso sexual; e que crianças e adultos com deficiência intelectual estariam em maior risco (Williams, 2003; Berastegui Pedro-Viejo \& Gomez-Bengoechea, 2006; Barros et al, 2008).

Procurando ampliar a compreensão sobre o que justificaria uma maior vulnerabilidade de crianças e adultos com deficiência a serem violentados, a literatura tem abordado uma série de fatores, que incluem aspectos da pessoa vitimizada e da própria deficiência, das famílias, da educação e sociais (Berastegui Pedro-Viejo \& GomezBengoechea, 2006). Entre os primeiros, estão aspectos entendidos como inerentes aos sujeitos em sua condição biológica diferenciada, dificultando a reação à violência ou mesmo seu reconhecimento. Quanto aos fatores familiares, problematizamos que, frequentemente, carregam em si uma concepção do contexto familiar de pessoas com deficiência como necessariamente problemático e sobrecarregado em função de possuir um membro com tal condição, o que acarreta o risco de serem naturalizadas e esperadas posturas inadequadas e mesmo violentas, justificadas pelo estresse e sofrimento vivenciado por seus cuidadores.

Além disso, e de extrema relevância, aparece o reconhecimento de aspectos da relação social e educativa com as pessoas com deficiência cuja análise se mostra imprescindível para a compreensão de uma vulnerabilidade aumentada à violência. Em geral, pessoas com deficiência não são educadas para adquirirem senso de autonomia, independência e autoproteção, tendo negadas suas habilidades e inserção social. Isso pode incluir um incentivo a que crianças, adolescentes e, mesmo, adultos com deficiência sempre se submetam à autoridade e ao desejo de outros, sejam ou não cuidadores, o que se relaciona a uma possível dificuldade de reconhecer ou retirar-se de circunstâncias que thes sejam prejudiciais. Observe-se que se trata, aqui, não de uma condição inerente a uma incapacidade inevitável do sujeito, resultante de um impedimento biológico determinado, mas de características específicas dos modos de socialização a ele permitidos. Do mesmo modo, observa-se uma tendência à negação ou patologização da sexualidade de indivíduos com deficiência. Isso, com grande possibilidade, redunda em um baixo nível de orientação acerca do tema, ausência de conhecimento quanto a convenções sociais 
aceitáveis e limites à manipulação do próprio corpo por si ou por outros, e carência de linguagem adequada para reconhecer, significar e denunciar abusos (Williams, 2003; Berastegui Pedro-Viejo \& Gomez-Bengoechea, 2006; Barros et al, 2008; Soares et al, 2008; Maia \& Ribeiro, 2010).

Adicionalmente, importa ressaltar que as pessoas com deficiência enfrentam, socialmente, condições como estigmatização, crenças negativas, falta de clareza sobre incapacidades e desvantagens, e de suporte a seu pleno desenvolvimento (Cavalcante \& Minayo, 2009). A desvalorização social e invisibilidade experimentadas por esses indivíduos contribui para que a não garantia de seus direitos fundamentais seja vista com naturalidade pela maioria da população. Segundo Berastegui Pedro-Viejo e Gomez-Bengoechea (2006), essa situação faz que as pessoas com deficiência sejam vistas, por possíveis perpetradores de violência, como menos poderosas, mais vulneráveis, menos capazes de revelarem a violência e com menos probabilidade de serem acreditadas se o fizerem. Existiria, ainda, uma falsa crença de que pessoas com comprometimentos de ordem desenvolvimental ou intelectual não possuiriam capacidade para compreender situações violentas e abusivas e, consequentemente, essas não Ihes causariam danos. Daí se observar, na revisão de literatura realizada pelos autores, que há uma tendência em desacreditar o testemunho de pessoas com deficiência e que, nos casos em que as revelações de violência são levadas em conta, há, frequentemente, encaminhamentos para cuidado médico em detrimento de medidas de apoio emocional, protetivas e de responsabilização dos agressores.

Consideramos essencial levar em conta, para uma compreensão mais crítica e abrangente acerca de uma maior vulnerabilidade de pessoas com deficiência a sofrer violência, que essa não se relaciona tãosomente a uma característica constitutiva dos sujeitos, à organicidade presumida de uma condição de diferenciação no desenvolvimento. Nesse sentido, concordamos com autores tais como Berastegui Pedro-Viejo e Gomez-Bengoechea (2006), Cavalcante e Goldson (2009) e Cavalcante e Minayo (2009), quando apontam que o risco aumentado não está relacionado à deficiência em si, ou mesmo a um possível estresse psicológico originado da necessidade de cuidado para com uma pessoa com deficiência. Relaciona-se, antes, com fatores sociais, culturais e econômicos que criam um imaginário social negativo sobre a questão. Nos mesmos trabalhos, esses estudiosos ressaltam que a forma como a deficiência estará combinada a diversos fatores entendidos como sendo de risco ou protetores seria o que nos auxiliaria a compreender a presença de uma possível maior vulnerabilidade à violência. A esse respeito, enfatizamos a necessidade de um olhar crítico diante do caráter 
complexo e dinâmico dos aspectos que a literatura aponta para se referir a risco ou proteção em face da violência (Wanderer, 2012). Uma conexão que se mostra promissora e apresenta desafios, tanto para a pesquisa quanto para a intervenção, refere-se às relações entre deficiência, violência e pobreza. Observa-se, atualmente, a existência de uma relação entre deficiência e pobreza, que suscita a necessidade de ações que explorem os mecanismos de suas correlações, atuando para modificá-las. Cavalcante e Goldson (2009) ressaltam a necessidade de que os temas deficiência, violência e pobreza passem a não mais ser tratados em separado, uma vez que coocorrem de forma expressiva. Apontam para a invisibilidade que parece existir acerca do fato de que a pobreza crônica afeta significativa parcela das pessoas com deficiência, o que as mantém sob o risco de crescimento da pobreza, piora de lesões e desordens mentais e de violência doméstica ou institucional. Para compreender tal fenômeno, enfatizam que a pobreza não deve ser concebida apenas sob o ângulo da carência monetária. Deve ser considerada, antes, como fenômeno multidimensional, relacionado à falta de provisão material associada com variados processos interdependentes de desigualdade, exemplificados por injustiças na distribuição do acesso à educação, a serviços de saúde, ao trabalho.

Encontramos, ainda, iniciativas que ressaltam a importância de se incluir o fator gênero nas pesquisas e propostas de intervenção. Guimarães (2008), enfatizando a crítica feminista à primeira fase do modelo social da deficiência ${ }^{2}$, coloca que, em sua maioria, são as mulheres que exercem o cuidado para com pessoas com deficiência. Analisando as formas pelas quais o Estado tem buscado oferecer assistência aos indivíduos com deficiência, aponta que há uma invisibilidade da vulnerabilidade enfrentada pelas cuidadoras, motivo pelo qual o gênero deve ser incluído na idealização de políticas públicas de cuidado. Almeida (2011) analisa o tratamento dado a ocorrências de violência doméstica contra mulheres com deficiência. $\mathrm{Em}$ tais casos, parece haver uma centralidade da deficiência em detrimento da questão de gênero, sendo que haveria uma maior tolerância em relação a episódios de violência contra mulheres com deficiência do que contra mulheres sem deficiência.

Assim, observamos que o tema da violência contra pessoas com deficiência ainda parece ser tão invisível quanto as próprias dificuldades enfrentadas por tais pessoas em função do modo como se processa sua socialização. Literatura científica escassa, com conclusões ainda pouco claras e consensuais, detecção de ausência ou falha de políticas públicas de cuidado e proteção são alguns dos aspectos identificados e que apontam para desafios de vulto no enfrentamento a tal questão. Nesse bojo, a deteç̧ão, a denúncia e as intervenções adequadas diante de situações de violência intrafamiliar contra pessoas com deficiência ainda são precárias. Um dos motivos 
para isso reside na insuficiente formação profissional crítica acerca dessa temática.

Concebemos que um primeiro passo para que se lide adequadamente com o fenômeno aqui abordado consiste em se trabalhar para tornálo público e notório, chamando a atenção para sua ocorrência, explicitando as dificuldades envolvidas, esclarecendo quanto aos direitos preconizados às pessoas com deficiência enquanto cidadãs. Conforme lembram Berastegui Pedro-Viejo e Gomez-Bengoechea (2006), é difícil que o Estado e a sociedade estejam preparados para atender às necessidades das pessoas com deficiência frente à violência se não há sensação de risco. Foucault (2003) ressalta que o ato de falar e denunciar situações configura uma luta contra formas estabelecidas de poder, não porque anteriormente ninguém estivesse consciente delas, mas sim porque representa uma primeira forma de forçar uma rede de informação institucional e inverter, por um momento que seja, as relações de poder, abrindo, assim, espaço para novas lutas.

\section{Deficiência e violência: o papel do Estado e da sociedade na promoção do cuidado}

A preocupação com a vulnerabilidade de pessoas com deficiência a sofrerem violência já aparece no artigo 16 da Convenção dos Direitos das Pessoas com Deficiência da Organização das Nações Unidas (ONU, recepcionada como Emenda Constitucional por nosso país (Brasil, 2009). Essa legislação atribui o papel de zelar pelo bem-estar e garantia dos direitos das pessoas com deficiência de não serem violentadas ao Estado. Para compreendermos qual o lugar a ser ocupado pelo Estado quanto ao tema, recorremos às reflexões de Guimarães (2008) em relação ao cuidado. A autora ressalta que o cuidado, tradicionalmente, é entendido como uma atividade necessária diante de pessoas em condição de dependência, característica desvalorizada socialmente, devendo ser exercido pela família e, mais especificamente, por mulheres (mães, esposas, filhas). Entretanto, lembra que a independência enquanto estado puro inexiste na vida em sociedade, quando os indivíduos se relacionam de forma interdependente. Adicionalmente, o cuidado deveria ser abordado como uma questão de justiça social e como um princípio ético que rege a vida em sociedade e implica o reconhecimento, por cada um, dos direitos e necessidades dos outros. Desse ponto de vista, o cuidado se configura como um direito e como dever do Estado e da sociedade, para além das fronteiras familiares. Nesse sentido, a autora ressalta que, mesmo ao se falar de promoção de independência e de autonomia, nos moldes em que se fazem factíveis, não se está diante da possibilidade da ausência ou 
da desnecessidade do cuidado. Assim, em situações em que há ausência ou abuso por parte da família que cuida, o Estado pode tomar para si ou compartilhar com essa família o cuidado.

Para além dessa forma de intervenção estatal, destacamos que o cuidado também se exerce por meio da elaboração e implementação de políticas públicas que permitam, de um lado, o suporte necessário às famílias de pessoas com deficiência, não apenas do ponto de vista material e, de outro, a garantia de direitos às pessoas com deficiência para que tenham asseguradas condições para seu pleno desenvolvimento. Isso exige intervenções em variadas frentes, tais como saúde, educação e mercado de trabalho. Requer, além disso, modificações nas relações sociais, que transformem a visão de menos valia que é conferida aos indivíduos com deficiência, desconstruindo a naturalização de ideias como a inferioridade, as incapacidades e limitações pressupostas em função de diferenças biológicas e a vinculação entre deficiência e sofrimento ou tragédia pessoal.

Apesar dos avanços nas legislações pertinentes à garantia de direitos das pessoas com deficiência, ainda não estamos diante de uma real sociedade inclusiva, cuja efetivação dependerá de lenta construção, importando que sejam tomadas atitudes pró-ativas por parte do poder público para que o acesso das pessoas com deficiência a uma estrutura social realmente democrática possa permitir o efetivo enfrentamento à temática da violência dirigida a elas (Cavalcante \& Minayo, 2009). A perpetuação do processo de exclusão social acarreta que as pessoas com deficiência não encontrem condições para o desenvolvimento de suas funções psicológicas superiores (planejamento, pensamento verbal e imaginação), dada sua desaparição do coletivo (Vigotski, 1931/1995). Isso Ihes dificulta o exercício da autodeterminação, da autonomia e, consequentemente, da autoproteção. Um dos efeitos perversos dessa circunstância refere-se à impossibilidade, enfrentada por muitas pessoas com deficiência, de acessarem, por conta própria, as instâncias e instituições sociais cujo objetivo volta-se à proteção e à garantia de direitos, ao implemento de programas e de políticas de prevenção à violência e à promoção de estratégias de tratamento, reabilitação e inserção social das vítimas de violência.

Em Wanderer (2012), foram analisados 10 casos atendidos pela equipe psicossocial do Serviço de Assessoramento aos Juízos Criminais do Tribunal de Justiça do Distrito Federal e dos Territórios (SERAV/TJDFT), que se referiam a situações de violência contra pessoas com deficiência. Nesse esforço, ficou evidenciado que elementos de estigmatização, quebra do direito ao pleno desenvolvimento e consequente exclusão social estiveram presentes em variados níveis em todas as situações.

Assim, compreendemos que, mais do que a preocupação com as várias formas de violência previstas na legislação que podem ser 
dirigidas às pessoas com deficiência, é de se ressaltar uma violência ainda maior, manifesta na aceitação tácita da invisibilidade social desses sujeitos e das consequências deletérias que tal circunstância acarreta para seu desenvolvimento.

\section{Considerações finais: desafios e perspectivas para a Psicologia}

A partir das análises empreendidas neste trabalho, entendemos poder apontar alguns aspectos que se referem a possíveis contribuições que a psicologia pode oferecer na construção de políticas públicas que atuem na minoração do fenômeno aqui focalizado. Inicialmente, consideramos essencial que a psicologia contribua para a desinvisibilização da violência contra pessoas com deficiência, por meio de um maior número de estudos e de um aprofundamento teórico que, conforme observamos, ainda se mostra incipiente, sobretudo no Brasil. Não é possível haver uma atuação social e estatal efetiva em relação a qualquer situação quando essa permanece obscurecida por práticas e atitudes que naturalizam processos de vulnerabilização e impedem a significação de determinados acontecimentos como violentos, dados os prejuízos que promovem para o desenvolvimento dos indivíduos afetados. É importante que as pessoas com deficiência sejam reconhecidas enquanto grupo vulnerável para que haja um investimento político que auxilie a fomentar maior produção de conhecimento, diversificar e complexificar reflexões e propor agendas de ações. Isso não implica naturalizar uma vitimização das pessoas com deficiência em função de uma condição imutável e inerente a elas, de forma irrefletida. Consiste, entretanto, em uma medida importante de um ponto de vista macro, para que haja uma abordagem concreta a tal fenômeno. Para contribuir, efetivamente, para uma maior visibilidade da violência contra pessoas com deficiência, percebemos que não basta apenas realizar descrições acerca das tipologias e naturezas das violências dirigidas contra pessoas com deficiência ou apontar que, em função dessa condição, há uma maior vulnerabilidade. Faz-se necessário, para além desses relevantes esforços, construir uma compreensão mais complexa e abrangente sobre a produção dessa vulnerabilidade, que é realizada nas dinâmicas relacionais, nos níveis interpessoais, familiares, comunitários e institucionais. É por meio dessa compreensão ampliada que será possível idealizar propostas de ação, já que permitirá reconhecer que a vulnerabilidade não reside nos próprios sujeitos, o que nos deixaria impotentes diante de realidades biológicas ou psicológicas que ainda não temos condições de alterar, mas repousa em processos sociais cuja criação, perpetuação ou mudança permanecem em nossas mãos. 
Além disso, cabe à psicologia oferecer conhecimentos acerca dos processos de desenvolvimento humano das pessoas com deficiência, atuando no sentido de compreendê-los de forma ampla, contínua e ilimitada, como já é realizado em relação aos sujeitos sem essa condição, ao menos em âmbito teórico. Isso requer a formulação de estudos nos quais haja delineamentos metodológicos que reconheçam e explicitem os pressupostos teóricos, epistemológicos e políticos com os quais se comprometem os pesquisadores. Acreditamos ser essencial a construção de metodologias que sejam, em si mesmas, empoderadoras e impulsionadoras do desenvolvimento dos sujeitos.

Urge que a psicologia dê maior atenção às diversas fases do ciclo de vida das pessoas com deficiência para além da infância, englobando adolescência, idade adulta e velhice, enfocando as especificidades e demandas próprias a tais momentos. Nesses estudos, concebemos ser essencial idealizar formas de dar voz a tais indivíduos, buscando acessar a complexidade de suas experiências subjetivas, incluindo a dimensão da deficiência e indo além dela, que frequentemente é tomada como eixo único e central de análise nas produções, atendendo, possivelmente, a uma projeção do estranhamento e do incômodo que essa condição provoca nos próprios pesquisadores.

Ressaltamos que, quando se fala em dar voz às pessoas com deficiência, em ouvir sobre suas experiências e considerar suas demandas na formulação de pesquisas e de ações públicas a elas dirigidas, não devemos perder de vista que a capacidade de se colocar nas arenas públicas e de significar as próprias experiências não é inata. É essencial que haja um investimento da sociedade para propiciar a tais sujeitos condições de desenvolvimento que thes permitam aprender sobre a existência e a utilidade da própria voz, bem como sobre seu direito e sobre as formas de empregá-la. Nesse sentido, enfatizamos que a rotulação dos indivíduos e o estabelecimento, a priori, de limites de desenvolvimento baseados no determinismo de características biológicas não é uma postura politicamente neutra ou atenta à objetividade científica. É, antes, ideológica, conforme a definição de ideologia oferecida por Chaui (1994) ${ }^{3}$.

Identificamos que a maior vulnerabilidade das pessoas com deficiência a sofrerem violência está diretamente ligada aos processos de discriminação, estigmatização e exclusão social, que ocorrem nas mais diversas relações e limitam seu desenvolvimento. Essa forma de socialização é, em si mesma, violenta. Assim, concebemos que políticas públicas que objetivem intervir diante desse fenômeno necessitam levar essa circunstância em conta, promovendo, antes de tudo, ações efetivas de fomentação de uma sociedade inclusiva, que permita condições mais igualitárias de desenvolvimento, respeitadas as diferenças individuais que compõem a inevitável diversidade 
humana. Considerar a violência contida nos processos de socialização desses indivíduos permitirá que o olhar para os episódios pontuais e específicos de violência, seja dentro ou fora da família, possa ser mais complexo e melhor contextualizado, suscitando intervenções que ocorram em múltiplos níveis e em rede. Tais intervenções devem compreender o caráter processual da violência, abarcando a necessidade de promover ações de empoderamento dos sujeitos e investindo no desenvolvimento de suas possibilidades de autocuidado e autoproteção. Também é necessário instrumentalizar profissionais e cidadãos em geral para reconhecerem e significarem situações que constituem violência contra pessoas com deficiência, no sentido de haver maiores possibilidades de suporte, notificação, apuração, responsabilização dos autores e efetivação de medidas de proteção. Adicionalmente, pensar em uma sociedade inclusiva acarreta a necessidade de investir em uma educação para os direitos e a cidadania, que deve ser dirigida a todos, independentemente da tipicidade ou atipicidade de seu desenvolvimento. Essa forma de educação emancipadora e estimuladora da autoconsciência em relação às próprias escolhas vincula-se ao impulso para a formação das funções psicológicas superiores, necessárias a habilidades tais como a autonomia, a autoestima, o autocuidado e a autoproteção. Conceber as possibilidades de autodeterminação dos indivíduos, entretanto, não anula a necessidade do cuidado. Esse deve ser compreendido como valor ético a ser desempenhado pela sociedade como um todo, não sendo aspecto requerido apenas por pessoas com deficiência. O cuidado implica o respeito às necessidades de cada um e é necessário ao longo da vida de todos, considerando que a vida em sociedade envolve sempre uma interdependência entre pessoas.

O Estado tem o dever de atuar no oferecimento do cuidado, que se manifesta na criação de estruturas de suporte aos indivíduos, famílias e comunidades, nos âmbitos da educação, da saúde, da assistência social, da criação e da aplicação de legislações que garantam seus direitos. Constituem formas desse cuidado tanto o oferecimento de condições para o pleno desenvolvimento, gerando, inclusive, a possibilidade de ações pessoais que minorem a própria vulnerabilidade, quanto a disponibilização de mecanismos de proteção externa aos sujeitos, quando forem identificados fatores que os vulnerabilizem. Esses fatores, quando existentes, devem ser levados em conta não apenas como sinais da necessidade de que outros atuem na proteção, como também de que haja ações que possam alterá-los por meio do impulso ao desenvolvimento dos indivíduos. O exercício do cuidado, assim, não deve significar a anulação da vontade e da autodeterminação subjetivas.

Acreditamos, finalmente, serem necessárias maiores reflexões acerca das tensões entre os âmbitos público e privado quando se fala acerca da atuação do Estado por intermédio de políticas públicas e 
legislações de enfrentamento à violência. Observamos, nas relações entre Estado e família, a presença de importantes contradições. Há um imaginário social que atribui às famílias a responsabilidade integral pelo cuidado de seus membros, notadamente quando são pessoas com deficiência. Isso pode levar a uma postura social e estatal de desresponsabilização e inação. Por outro lado, as famílias cobram do Estado ações de suporte que, frequentemente, não recebem, ao mesmo tempo em que podem se sentir invadidas em suas funções quando há uma intervenção externa em sua dinâmica de funcionamento. Importa viabilizar e ampliar debates que permitam se pensar a intervenção do Estado, o exercício de seu poder, como uma forma de cuidado e não de violência, ainda que seja identificada uma relação assimétrica de poder entre os âmbitos público e privado. Tratamos das complexidades envolvidas na compreensão da violência contra pessoas com deficiência, enfatizando haver um caráter simbólico e estrutural contido na dinâmica social mais ampla, o que inaugura importantes desafios para a psicologia e áreas afins. Entretanto, não concebemos que isso deva nos levar a posturas de imobilismo e impotência, ou à realização de leituras reducionistas que recortem o objeto em fatias mais palatáveis. Desafios são elementos que devem ser impulsionadores da ação, da investigação, do trabalho, da criação e da inovação.

\section{Referências}

Almeida, A. J. L. (2011). Vulnerabilidade de mulheres com deficiência que sofrem Violência. Monografia de Especialização, Universidade de Brasília, DF, Brasília, Brasil. Recuperado em 28 de agosto, 2012,

de: http://bdm.bce.unb.br/bitstream/10483/2596/1/2011_HaynaraJoc elyLimadeAlmeida.pdf

Aranha, M. S. F. (2001). Paradigmas da Relação entre a Sociedade e as Pessoas com Deficiência. Revista do Ministério Público do Trabalho, Editora LTr, 11(21), 160-173.

Assis, S. G. (2009). Children and youth with and without disabilities. Ciência \& Saúde Coletiva, 14(1), 26-29. Recuperado em 22 de outubro, 2010, de: http://www.scielo.br/scielo.php?script=sci_arttext\&pid=S1413$81232009000100006 \&$ Ing $=$ pt\&nrm $=$ iso

Barros, R. D., Williams, L. C. A., \& Brino, R. F. (2008). Habilidades de auto proteção acerca do abuso sexual em mulheres com deficiência mental. Revista Brasileira de Educação Especial, 14(1), 93-110. Recuperado em 09 de setembro, 2010, de: http://www.scielo.br/scielo.php?script=sci_arttext\&pid=S1413$65382008000100008 \&$ lng $=$ en\&nrm=iso 
Bastos, O. M., \& Deslandes, S. F. (2009). Adolescer com deficiência mental: a ótica dos pais. Ciência \& Saúde Coletiva, 14(1), 79-87. Recuperado em 14 de Julho, 2012, de: http://www.scielo.br/scielo.php?script=sci_arttext\&pid=S1413$81232009000100013 \&$ lng $=$ pt\&nrm=iso

Berastegui Pedro-Viejo, A., \& Gomez-Bengoechea, B. (2006). Los menores con discapacidad como víctimas de maltrato infantil: una revisión. Intervención Psicosocial, 15(3), 296-306. Recuperado em 27 de julho, 2012, de:

http://scielo.isciii.es/scielo.php?script=sci_arttext\&pid=S113205592006000300004\&lng=es\&nrm=iso

Brasil. (2009). Decreto $n^{\circ}$. 6.949/2009. Promulga a Convenção Internacional sobre os Direitos das Pessoas com Deficiência e seu Protocolo Facultativo, assinados em Nova York, em 30 de março de 2007. Brasília. Recuperado em 10 de setembro, 2010, de http://www.planalto.gov.br/ccivil_03/_ato20072010/2009/decreto/d6949.htm

Cavalcante, F. G., \& Goldson, E. (2009). Situational analysis of poverty and violence among children and youth with disabilities in the Americas: an agenda proposal. Ciência \& Saúde Coletiva, 14(1), 720. Recuperado em 03 de janeiro, 2012, de: http://www.scielo.br/scielo.php?script=sci_arttext\&pid=S1413$81232009000100002 \&$ lng $=$ pt\&nrm=iso

Cavalcante, F. G., \& Minayo, M. C. S. (2009). Representações sociais sobre direitos e violência na área da deficiência. Ciência \& Saúde Coletiva, 14(1), 57-66. Recuperado em 03 de janeiro, 2012, de: http://www.scielosp.org/scielo.php?script=sci_arttext\&pid= $\mathrm{S} 1413-81232009000100011 \& \mathrm{lng}=\mathrm{en} \& \mathrm{nrm}=$ iso

Chaui, M. (1984). Participando do debate sobre mulher e violência. In R. Cardoso, R. (Org.). Perspectivas antropológicas da mulher: sobre mulher e violência (Vol. 4, pp. 25-62). Rio de Janeiro: Zahar.

Chaui, M. (1994). O que é Ideologia. (37a ed.). São Paulo: Editora Brasiliense.

Clímaco, J. (2010). Discursos Jurídicos e Pedagógicos sobre a Diferença na Educação Especial. Dissertação de Mestrado, Facultad Latinoamericana de Ciencias Sociales, Buenos Aires, Bs As, Argentina.

Cruz, M. C., Silva, J. T., \& Alves, H. C. (2007). Evidências sobre violência e deficiência: implicações para futuras pesquisas. Revista Brasileira de Educação Especial, 13(1), 131-146. Recuperado em 30 de agosto, 2010,

de:

http://www.scielo.br/scielo.php?script=sci_arttext\&pid=S141365382007000100009\&lng=en\&nrm=iso

Dias, S. S. (2004). O sujeito por trás do rótulo: significações de si em narrativas de estudantes de ensino médio com indicação de 
deficiência mental. Dissertação de Mestrado, Universidade de Brasília, DF, Brasília, Brasil.

Foucault, M. (2003). A microfísica do poder (R. Machado, Trad., $21^{\text {a }}$ ed.). Rio de Janeiro: Graal (trabalho original publicado em 1979).

Galinkin, A. L. (2007). Velhas e Novas violências contra a mulher. In Procuradoria Regional do Trabalho de Goiás (Org.). Mulher, Gênero e Relações de Trabalho (pp. 12-27). $1^{\text {a }}$ ed. Goiânia. p. 12-27. Recuperado em 13 de outubro, 2011, de: http://www.prt18.mpt.gov.br/eventos/2007/mulher/anais/artig os/ana_lucia.pdf

Gould, S. J. (1991). A falsa medida do homem. (V. L. Siqueira, Trad.). São Paulo: Martins Fontes (trabalho original publicado em 1981).

Guimarães, F. (2010). Mas ele diz que me ama...: impacto da história de uma vítima na vivência de violência conjugal de outras mulheres. Dissertação de Mestrado, Universidade de Brasília, DF, Brasília, Brasil.

Guimarães, R. (2008). Deficiência e cuidado: por quê abordar gênero nessa relação?. SER Social, 10(22), 213-238.

Krug, E. G., Dahlberg, L. L., Mercy, J. A., Zwi, A. B., \& Lozano, R. (2002). Relatório mundial sobre violência e saúde. Geneva: Organização Mundial da Saúde. Recuperado em 13 de outubro, 2011, de http://www.opas.org.br/cedoc/hpp/ml03/0329.pdf

Lacerda, P. M. (2006). De Perto, Ninguém é Anormal: a construção discursiva de identidades, em narrativas de trajetórias escolares longas, de pessoas com deficiência. Tese de Doutorado, Pontifícia Universidade Católica do Rio de Janeiro, Rio de Janeiro, RJ, Brasil.

Linton, S. (1998). Reassigning meaning. In S. Linton( Ed.). Claiming disability. p. 8-33. New York: New York University Press.

Maia, A. N. C. P., \& Ribeiro, P. R. M. (2010). Desfazendo mitos para minimizar o preconceito sobre a sexualidade de pessoas com deficiência. Revista brasileira de Educação Especial, 16(2), 159176. Recuperado em 21 de dezembro, 2012, de: http://www.scielo.br/scielo.php?script=sci_arttext \&pid $=$ S1413-65382010000200002\&Ing $=$ pt\&nrm $=$ iso

Medeiros, M. N. (2010). Violência conjugal: repercussões na saúde mental de mulheres e suas filhas e seus filhos adultas/os jovens. Dissertação de mestrado, Universidade de Brasília, DF, Brasília, Brasil.

Messa, A. A., \& Fiamenghi Jr, G, A. (2010). O impacto da deficiência nos irmãos: histórias de vida. Ciência \& Saúde Coletiva, 15(2), 529-538. Recuperado em 14 de julho, 2012, de: http://www.scielo.br/scielo.php?script=sci_arttext\&pid=S1413$81232010000200029 \&$ Ing $=$ pt\&nrm =iso 
Minayo, M. C. S. (2009). Conceitos, teorias e tipologias de violência: a violência faz mal à saúde individual e coletiva. In K. Njaime, S. G. Assis, \& P. Constantin (Orgs.). Impactos da Violência na Saúde (pp. 21-420). Rio de Janeiro: Fundação Oswaldo Cruz, $2^{\mathrm{a}} \mathrm{Ed}$.

Omote, S. (1994). Deficiência mental e não-deficiência: recortes do mesmo tecido. Revista Brasileira de Educação Especial, 1(2), 65-73.

Pessotti, I. (1981). Sobre a gênese e evolução histórica do conceito de deficiência mental. Revista Brasileira de Deficiência mental, 16(1), 54-69.

Postalli, L. M. M., Munuera, R. F., \& Aiello, A. L. R (2011). Caracterização de família de mãe com deficiência intelectual e os efeitos no desenvolvimento dos filhos. Revista Brasileira de Educação Especial, Marília, 17(1), 37-52. Recuperado em 11 de Julho, 2012, de: http://www.scielo.br/scielo.php?script=sci_arttext\&pid=S1413$65382011000100004 \& \operatorname{lng}=$ en\&nrm = iso

Schiff, M. (1994). A inteligência desperdiçada: desigualdade social, injustiça escolar (W. Settineri, Trad.). Porto Alegre: Artes Médicas (trabalho original publicado em 1982).

Schraiber, L. B., D'Oliveira, A. F. P. L., \& Couto, M. T. (2006). Violência e saúde: estudos científicos recentes. Revista de Saúde Pública, 40(esp.), 112-120. Recuperado em 13 de outubro, 2011 , http://www.scielosp.org/pdf/rsp/v40nspe/30630.pdf

Soares, A. H. R., Moreira, M. C. N., \& Monteiro, L. M. C. (2008). Jovens portadores de deficiência: sexualidade e estigma. Ciência \& Saúde Coletiva, 13(1), 185-194. Recuperado em 21 de dezembro, 2010, de: http://www.scielo.br/scielo.php?script=sci_arttext\&pid=S1413$81232008000100023 \&$ lng $=$ pt\&nrm $=$ iso

Tunes, E., Rangel, R. B., \& Souza, J. (1992). Sobre a Deficiência Mental. Revista Integração, 4(10), 10-12.

Tunes, E., \& Danezy Piantino, L. (2001). Cadê a síndrome de Down que estava aqui? O gato comeu: O programa da Lurdinha. Campinas: Autores associados.

Tunes, E. (2003). Por que falamos de inclusão? Linhas críticas, 9(16), $5-12$.

Vigotski, L. S. (1995). Fundamentos de defectologia. In L. S. Vigotski. Obras completas (Volume V). p. 1-40. Havana: Editorial Pueblo y Educación (trabalhos originais produzidos e/ou publicados entre 1924 e 1935).

Wanderer, A. (2012). Violência intrafamiliar contra pessoas com deficiência: discutindo vulnerabilidade, exclusão social e as 
contribuições da psicologia. Dissertação de mestrado, Universidade de Brasília, DF, Brasília, Brasil.

Wieviorka, M. (2007). Violência hoje. Ciência \& Saúde Coletiva, 11(sup.), 1147-1153. Recuperado em 12 de outubro, 2011, de: http://www.scielo.br/scielo.php?script=sci_arttext\&pid=S1413$81232006000500002 \& \operatorname{lng}=$ en\&nrm $=$ iso

Williams, L. C. A. (2003). Sobre deficiência e violência: Reflexões para uma análise de revisão de área. Revista Brasileira de Educação Especial, 9(2), 141-154.

\section{Endereço para correspondência \\ Aline Wanderer}

Tribunal de Justiça do Distrito Federal e dos Territórios

SMAS, Trecho 3 Lotes 4/6 Bloco 2, $2^{\circ}$ andar, Fórum Júlio Leal Fagundes, CEP 70610-906, Brasília - DF, Brasil

Endereço eletrônico: aline.wanderer@gmail.com

\section{Regina Lúcia Sucupira Pedroza}

Instituto de Psicologia/Departamento de Psicologia Escolar e do Desenvolvimento Campus Darcy Ribeiro UnB, Instituto Central de Ciências, Gleba A, CEP 90910-900, Brasília - DF, Brasil

Endereço eletrônico: rpedroza@unb.br

Recebido em: 18/07/2014

Reformulado em: 06/10/2014

Aceito para publicação em: 13/01/2015

\section{Notas}

* Psicóloga do Tribunal de Justiça do Distrito Federal e dos Territórios (TJDFT) Brasília - DF. Mestre em Processos de Desenvolvimento Humano e Saúde Universidade de Brasília (UnB).

** Professora Doutora do Instituto de Psicologia da Universidade de Brasília (UnB)

- DF. Possui Doutorado com Pós-doutorado.

${ }^{1}$ Ao tratar das teorizações acerca do modelo social da deficiência, optamos por citar alguns termos em inglês, uma vez que não há acordo, entre os autores, em relação a traduções que consigam exprimir, com precisão, o que se busca expressar na língua original. Isso ocorre não apenas com o termo disability, mas também com outros a ele relacionados: impairment, disability studies e ableism.

2 A crítica feminista, que veio à tona na segunda geração do modelo social da deficiência (cujas primeiras formulações datam da década de 70 do século $X X$ ), inseriu na discussão os temas do cuidado (majoritariamente exercido por mulheres), da experiência da dor, da lesão e do corpo doente, e da interdependência como condição indispensável à vida social (Guimarães, 2008).

${ }^{3}$ Chaui (1994) define ideologia como um conjunto de ideias que se pretendem ahistóricas e, por isso, justificam a si mesmas e não permitem movimentos de problematização e modificação. 